\title{
Using mobile technology to promote safe sex and sexual health in adolescents: current practices and future recommendations
}

This article was published in the following Dove Press journal:

Adolescent Health, Medicine and Therapeutics

5 April 2016

Number of times this article has been viewed

\section{Judith B Cornelius'}

Josephine A Appiah²

'School of Nursing, ${ }^{2}$ Health Services Research Doctoral Program, College of Health and Human Services, University of North Carolina at Charlotte, Charlotte, NC, USA



Correspondence: Judith B Cornelius School of Nursing, University of North Carolina at Charlotte, 920I University City Blvd, Charlotte, NC, 28223, USA

Tel +I 7046877978

Email jbcornel@uncc.edu

\begin{abstract}
Youth and young adults (19-24 years of age) shoulder the burden of sexually transmitted infections accounting for nearly half of all new infections annually. Mobile technology is one way that we have reached this population with safer sex information but challenges exist with the delivery process. The literature between 2010 and 2015 was reviewed for data on safe sex and sexual health information delivered using mobile cell phone devices. A search for relevant databases revealed that 17 articles met our inclusion criteria. Findings suggest that mobile cell phone interventions are an effective mode for delivering safe sex and sexual health information to youth; those at the highest risk may not be able to access cell phones based on availability and cost of the text messages or data plans.
\end{abstract}

Keywords: mobile, safe sex, sexual health, practices, recommendations

\section{Introduction}

According to the Centers for Disease Control and Prevention, nearly 19.7 million sexually transmitted infections (STIs) occur each year. ${ }^{1}$ While preventable, these infections are a major health concern because of the probability that those infected will be reinfected with the same STI or a new one. Youth and young adults (19-24 years of age) account for nearly half of the new infections, ${ }^{1}$ primarily as a result of risky sexual behaviors. Among high school students surveyed in the 2013 Youth Behavior Surveillance Survey, ${ }^{2} 47 \%$ reported having had sexual intercourse, $34 \%$ had had sexual intercourse during the previous 3 months, and of these $41 \%$ did not use a condom the last time they had sex. Additionally, $15 \%$ of the youth had had sex with four or more people during their life, and only $22 \%$ reported having ever been tested for HIV.

Mobile technology has become a popular option for delivering safer sex interventions for adolescents. According to a Pew Research Center survey, $78 \%$ of teens now have a cell phone and almost half (47\%) own Smartphones. ${ }^{3}$ One in four teens (23\%) has a tablet computer, and $93 \%$ have a computer or have access to one at home. In addition, seven in ten $(71 \%)$ have access to a laptop or desktop that is shared with family members, making access to social media sites and text messaging a safer sex health promotion option. However, despite the increased use of mobile technology, it remains unclear how effective safer sex education is in reducing sexual risk behaviors. Accordingly, we conducted a review of the literature to examine current practices and recommendations for future use of mobile technology for promoting sexual health and reducing the risk of STIs among youth. 


\section{Methods}

Studies were included in the review if they: 1) were original reports; 2) pertained to sexual health; 3) used a quantitative or qualitative research design; 4) involved adolescents or had the word adolescent in the title; 5) were published in a peer reviewed journal; and 6) were conducted within the past 5 years. Studies were excluded if published in languages other than English. Based on the National Institutes of Health definition of a child ${ }^{4}$ and the World Health Organization definition of adolescence, we set the upper age limit of 20 years and the lower age limit of 12 years for adolescence. ${ }^{5}$ We defined safe sex as the ability to prevent oneself and a sexual partner from contracting an STI or becoming pregnant by using protective devices, such as condoms or dental dams.

The literature review was conducted using PyscInfo, PubMed, CINAHL, Medline, and Cochrane Review databases from 2010 to 2015. The following search terms were used: research, adolescent, safer sex, sexual education, sexuality programs, and mobile technology (text messaging and mobile phones). Reference lists from each article were reviewed for additional citations, and those meeting the inclusion criteria were added. Relevant studies were also uncovered by doing a manual search in journals that published articles on mobile technology and sexual health. A total of 295 abstracts were retrieved and 17 articles met the inclusion criteria (see Figure 1). Each study was read and coded according to the study purpose, design, sample, measures, major findings, and limitations. All extracted data were then read, coded, and discussed by the two authors who compared their coding and preliminary findings to confirm the accuracy of their interpretations for each study (Miles and Huberman). ${ }^{6}$ Table 1 provides the citations and key components of the studies.

\section{Results}

\section{Study designs}

Ten of the 17 studies used quantitative methods. Four studies were longitudinal with repeated measures ${ }^{7-10}$ and the other quantitative studies used descriptive or cross-sectional

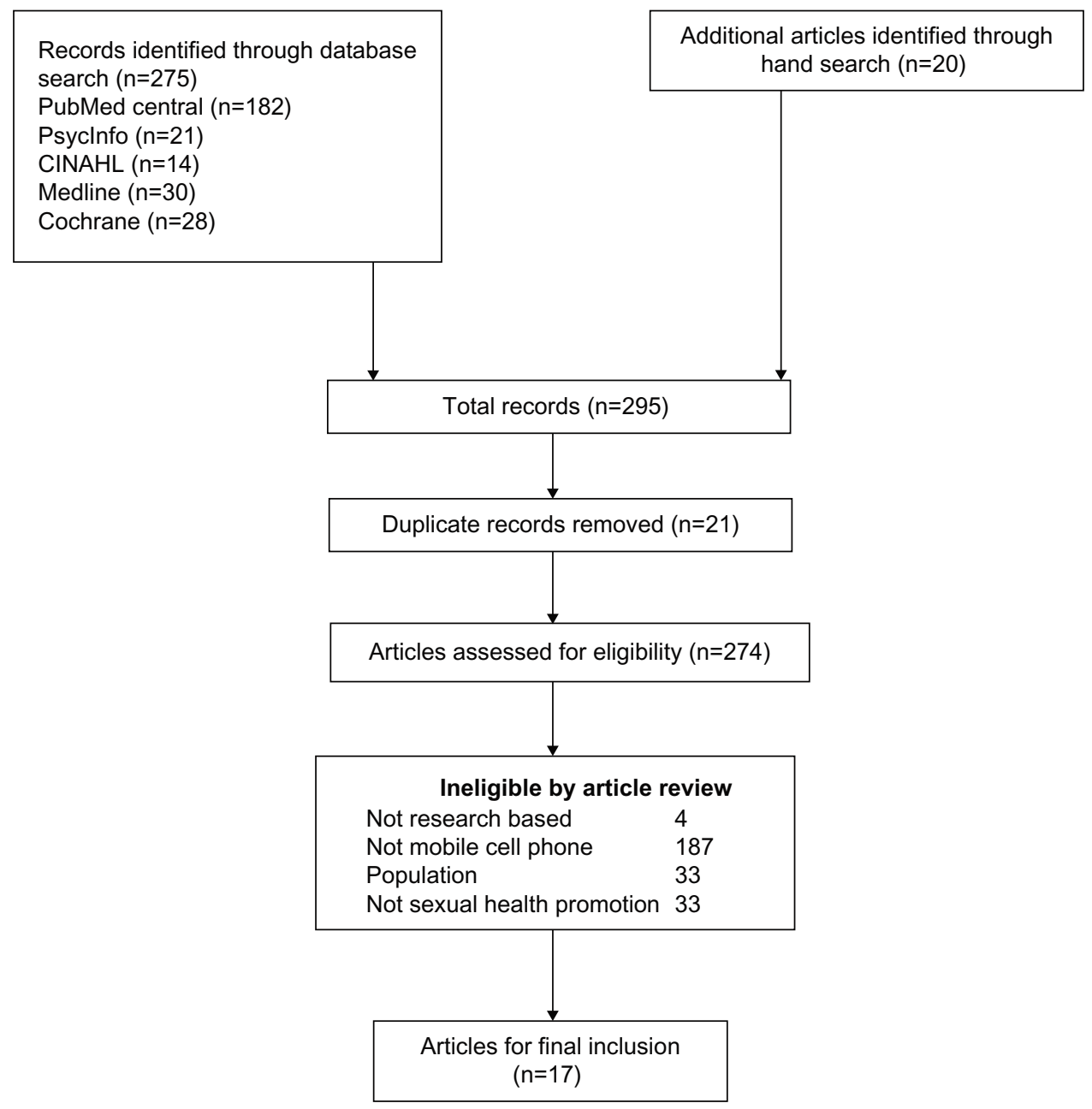

Figure I Inclusion/exclusion data. 
designs. ${ }^{11-14}$ One study was a randomized trial $;{ }^{8}$ the others were a one-group pre-/posttest design ${ }^{7}$ and a nonrandomized control group design. ${ }^{9}$ Three studies used mixed methods, ${ }^{15-17}$ one was constructed in Africa ${ }^{18}$ and the others used qualitative designs, with interviews or focus groups. ${ }^{19-22}$ Intervention lengths varied from 4 weeks ${ }^{16,17}$ to 3 months. ${ }^{7,9,10}$ Text messaging or mobile cell phone follow-up periods ranged from posttest, ${ }^{16,17}$ weekly, ${ }^{7,9} 3$ months $^{9,11,22}$ to 24 months $^{8}$; most studies were formative or pilot studies, and used validated measures to assess intervention outcomes. All studies used self-reported data with the exception of two; one used STI biomarkers in addition to self-reported data ${ }^{11}$ and the other used early pregnancy tests in addition to self-reported data. ${ }^{8}$ Sample sizes varied from eleven to 1,738 participants. Four studies discussed theories used to guide development of the text messages/interventions. ${ }^{10,15,16,22}$ These theories included empowerment theory, social capital theory, theory of reasoned action, health belief model, ${ }^{10,22}$ youth asset developmental theory, ${ }^{16}$ and ADAPTITT model. ${ }^{15}$ The text-messaging dosage varied among interventions from one message per day, ${ }^{7,11}$ weekly, ${ }^{20}$ three per week $^{9,10}$ to eleven per week. ${ }^{17}$ Mobile cell phone counseling calls occurred once weekly. ${ }^{8}$ Only one study discussed analysis of an HIV-prevention website enhanced for mobile cell phone text-messaging delivery. ${ }^{23}$ Over a 14 -month time period, the website had a total of 2,125 unique visitors from 61 different countries. Another study discussed data from a sexual health text message service designed for youth to determine the type of confidential questions asked by participants. ${ }^{13}$

\section{Delivery process}

Several studies identified challenges involved in the development of text messages for mobile cell phone delivery. In one study, participants noted that some of the textmessaging abbreviations were not helpful. ${ }^{15}$ Further, areas of inaccuracy and confusion were found. For example, one teen was unsure whether mosquitoes could transmit HIV even after the correct information was provided. Whenever teens got the answer wrong, they felt they should be able to text a facilitator to clarify why the response was wrong. In another study, participants felt that the initial text messages blamed or stigmatized the African-American community and recommended that messages be geared to the young black population. ${ }^{22}$ Participants also noted that messages should be factual, respectful, and humorous. One suggested format was starting with humor, then finishing with a fact. Participants in one study found that a mobile phone application (app) was difficult to read and use, was not tailored to the intended population, and raised privacy issues. ${ }^{17}$
Technical problems also presented challenges. ${ }^{15,17}$ In one study, the research team identified errors in the message delivery process as well as equipment problems, including failure of the short messaging service to send the message at the specified time, inability to receive text messages, and failure to respond to the messages as the result of a lost or damaged cell phone. ${ }^{15}$ All of the problems were corrected, however. In the same study, problems in downloading videos or viewing URL links were found to be challenges. The researchers noted, however, that including a tech facilitator on the research team who could quickly correct problems reduced frustration and dropout rates. ${ }^{15}$ In one study, the researchers found that they had to replace a participant's phone, which had been stolen, and had to turn off two cell phones when teens went over their allocated minutes before the end of the month. ${ }^{17}$ In another study, some teens lost or damaged their phones or were out of contact for an extended period of time resulting in considerable variability in participation rates. ${ }^{8}$

The cost of delivering text-messaging interventions was also a challenge and in two studies, mobile cell phones were given to participants to offset costs. ${ }^{15,17}$ However, given current unlimited text-messaging plan, this is no longer a major barrier to adoption of text-messaging interventions. In the Teen Outreach Program, the buddy system was used. Teens with a mobile phone shared their phone or read the messages to a peer (their buddy) who did not have access to a mobile phone. This process did not work uniformly with some teens deleting messages before their buddy could read them. ${ }^{16}$ In another study, the mobile phone incentive diminished as the low cost of prepaid cell phones became readily available and many of the teens purchased their own personal cell phone by the end of the study. ${ }^{17}$

\section{Lack of longitudinal studies}

Only two of the studies reported outcomes beyond the 3-month follow-up ${ }^{9,10}$ and only one included 24-month follow-up. ${ }^{8}$ Thus, only short-term effects of mobile cell phone interventions have been reported. Juzang et $\mathrm{al}^{9}$ found significant changes in three key outcomes: higher condom use, increased sexual health awareness, and increased monogamy postintervention. In another study, HIV knowledge, attitudes toward condom use, and perceived HIV risk increased while HIV risk behaviors decreased at 3-month follow-up. ${ }^{7}$

\section{Privacy issues}

In two studies, adolescents identified issues of privacy and lack of anonymity as possible challenges in delivering text 


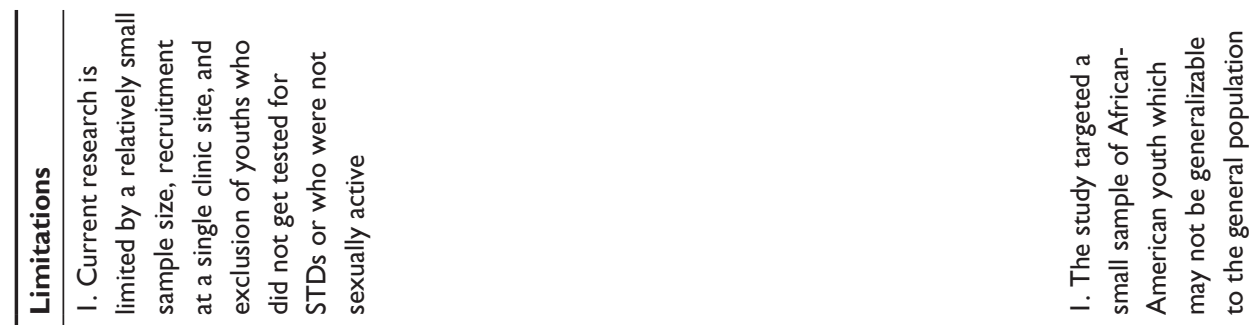

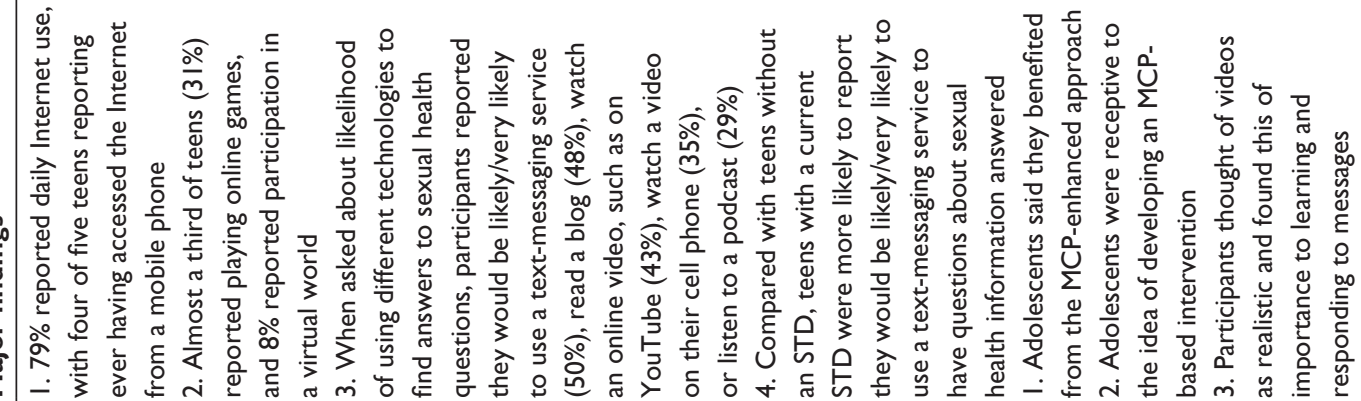
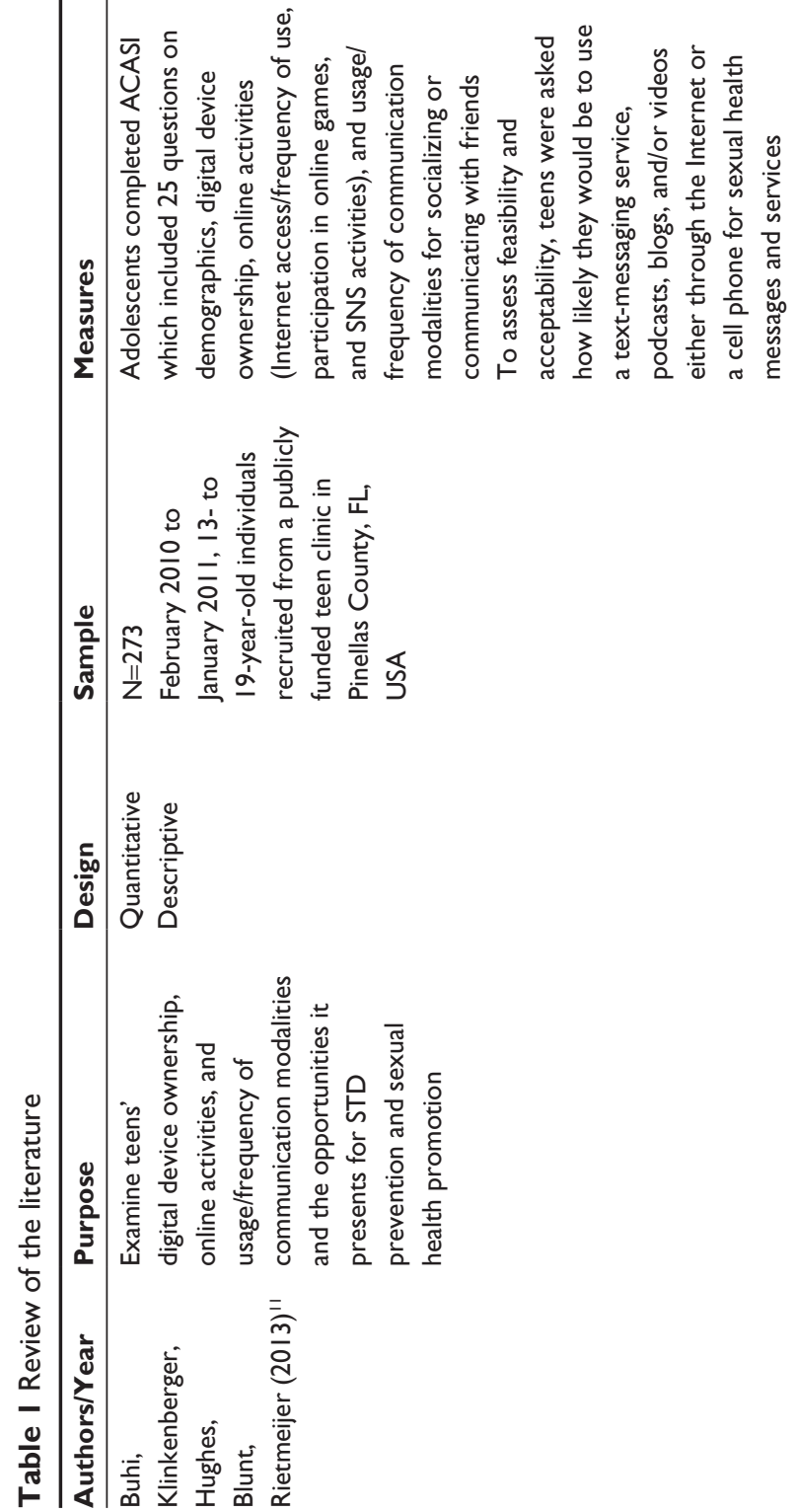

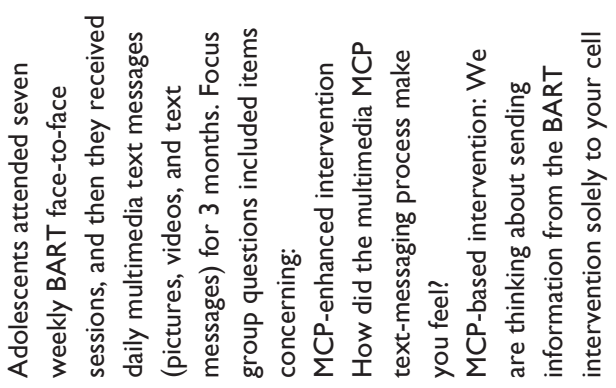

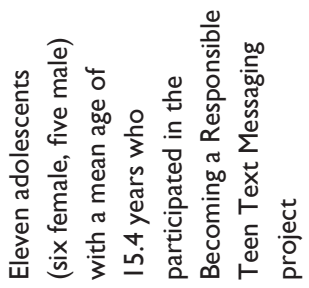

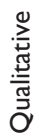
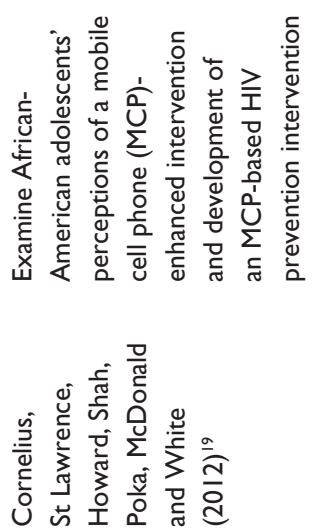



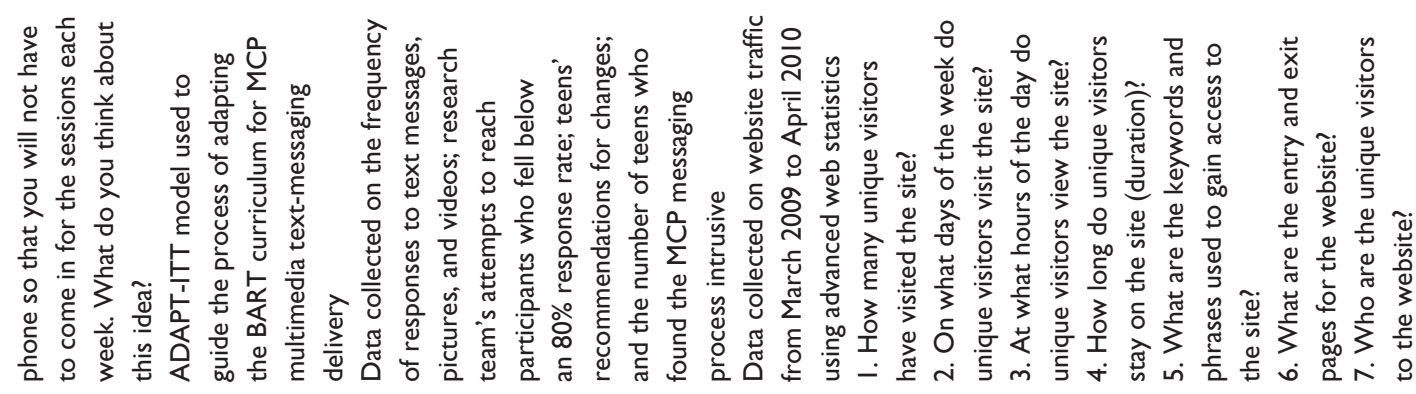
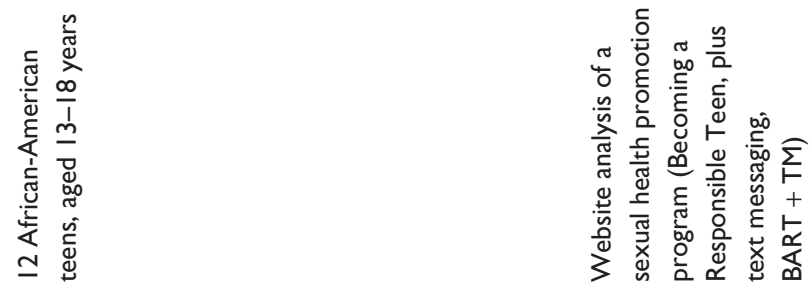

总营

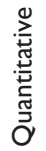
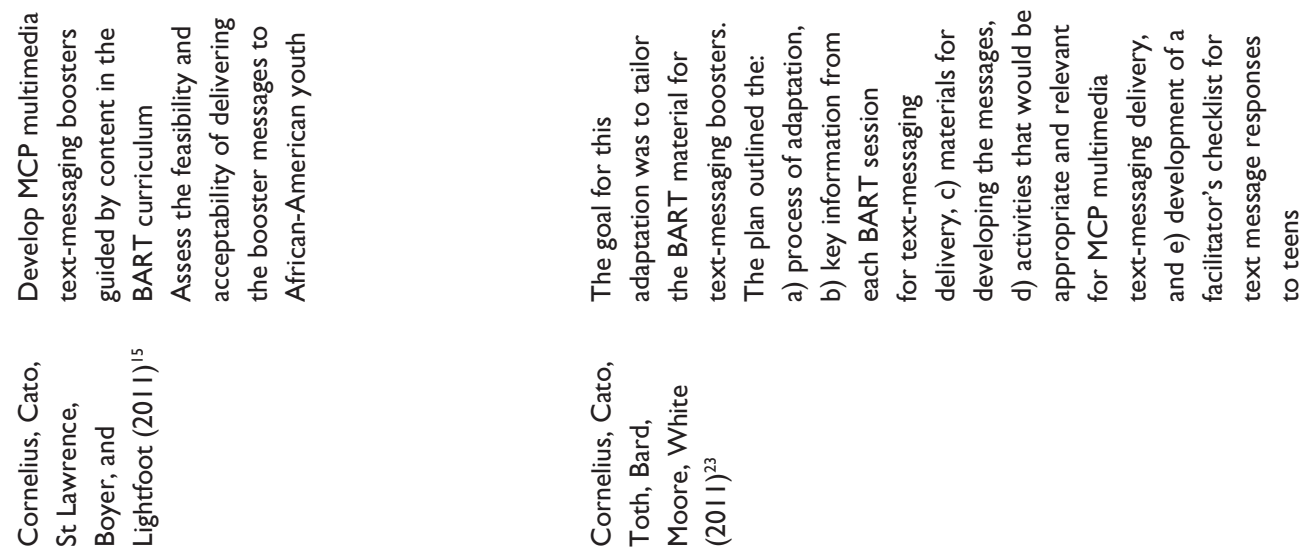


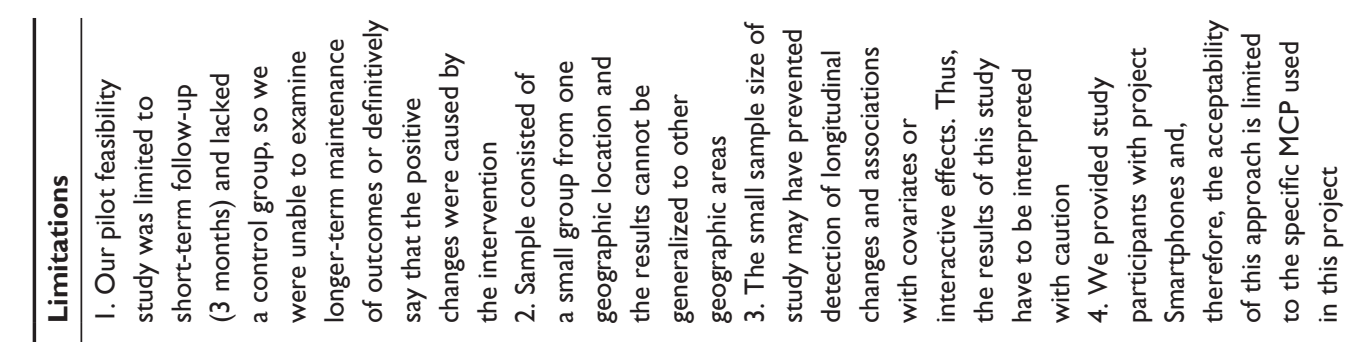



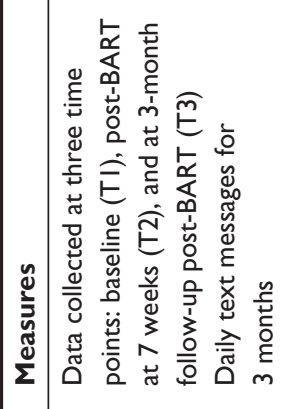

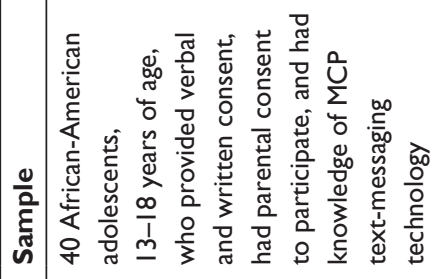

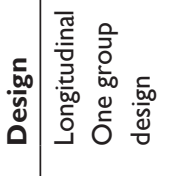

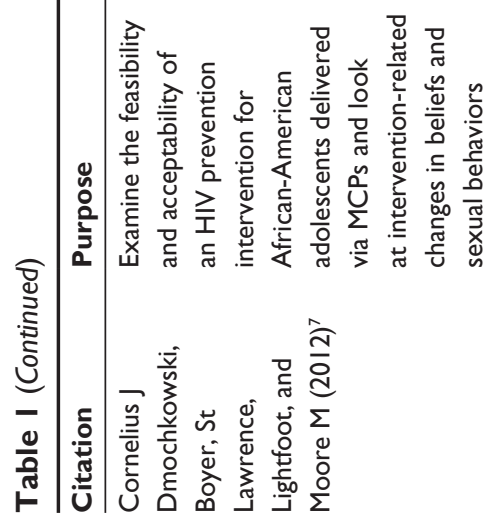




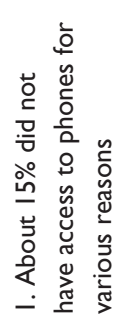

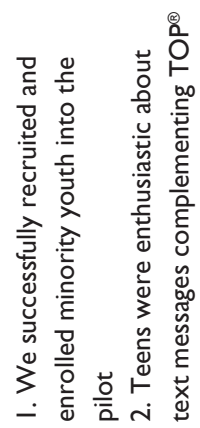

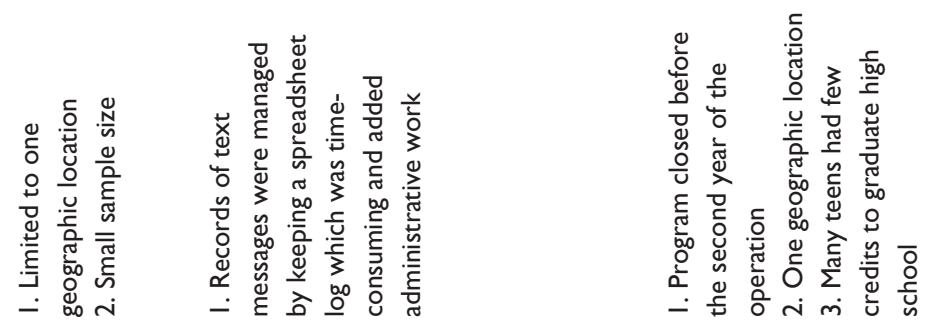

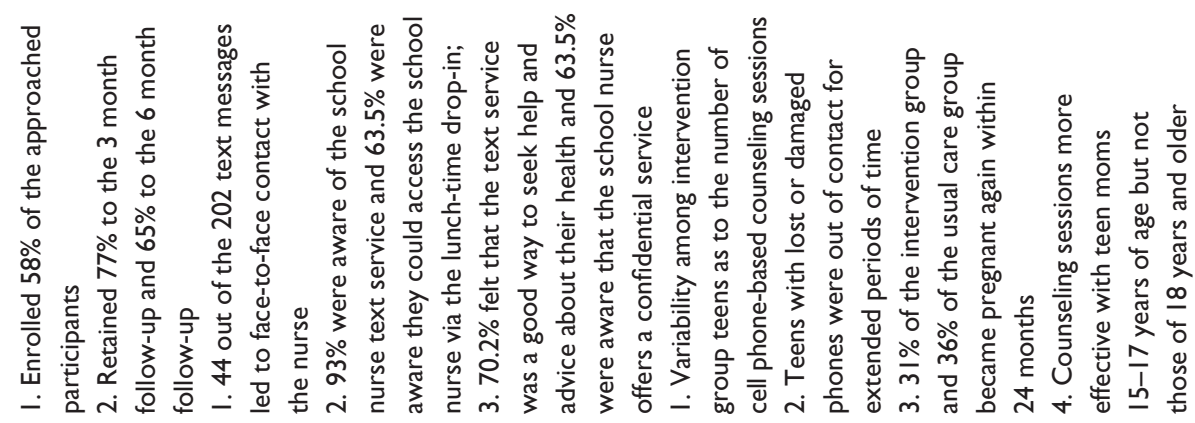

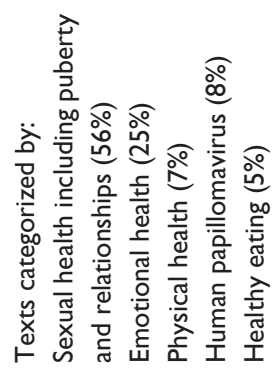

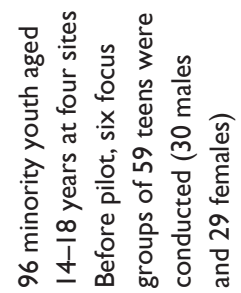

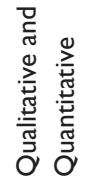

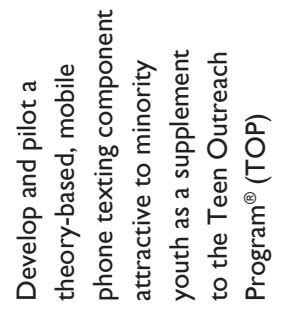

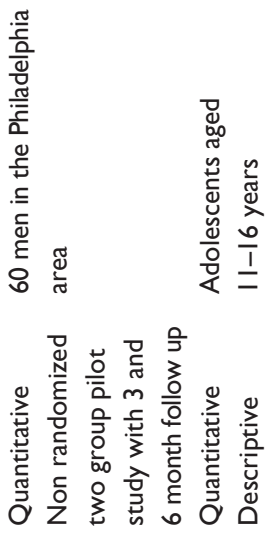
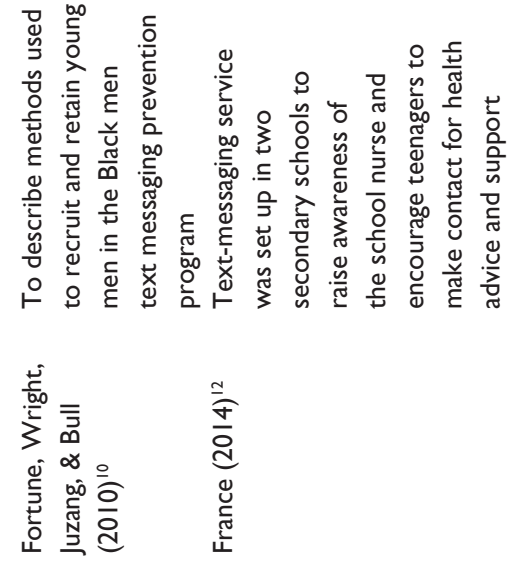
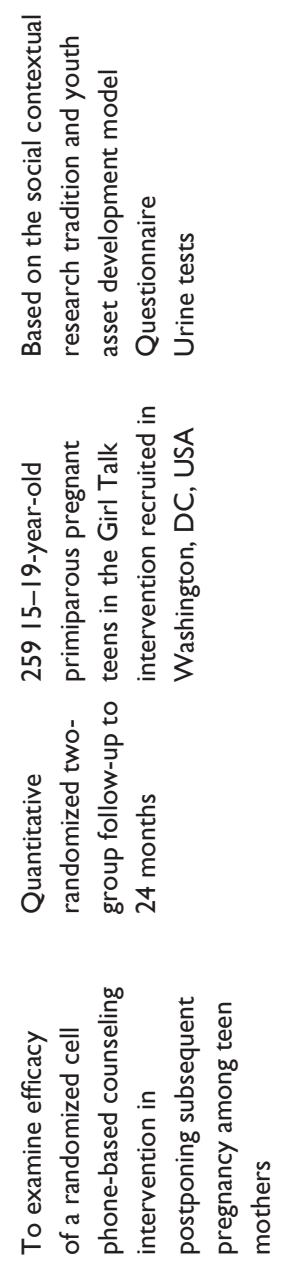

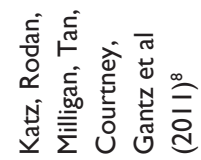




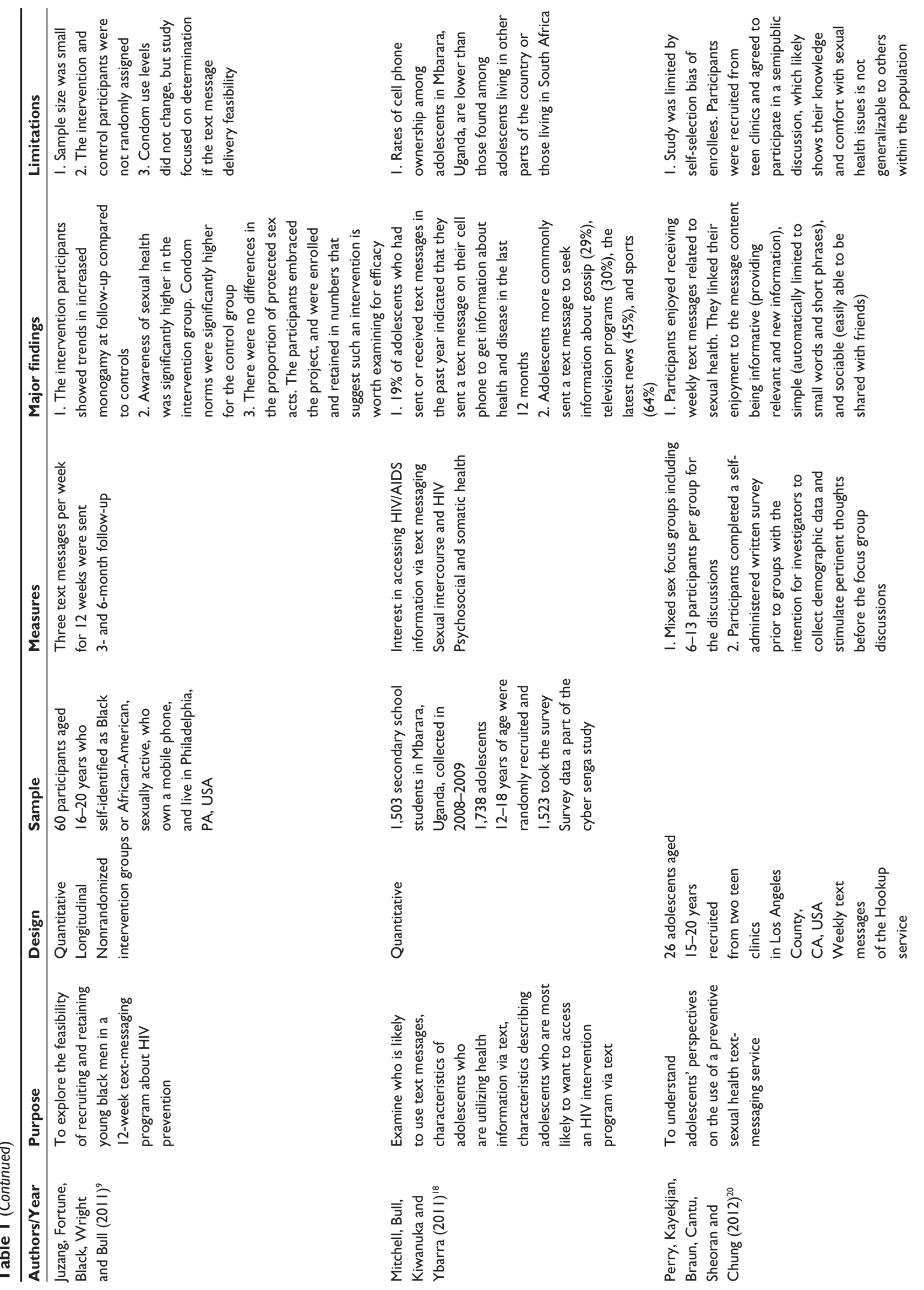




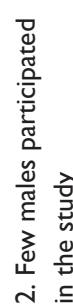

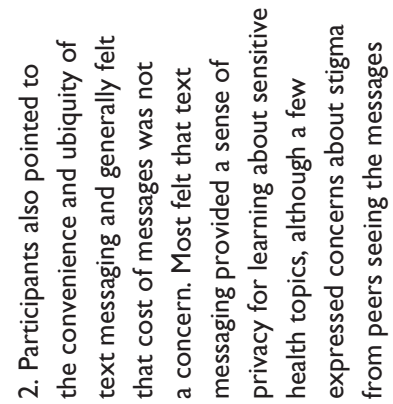

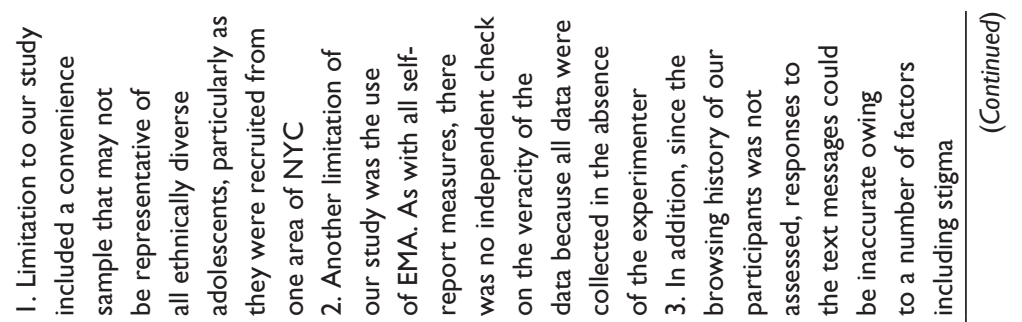

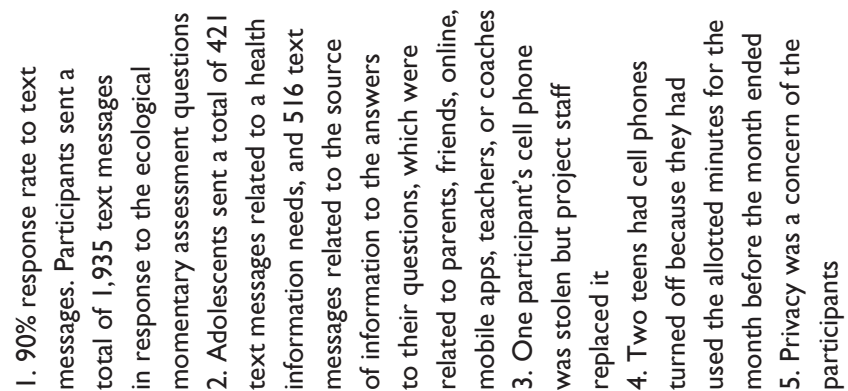

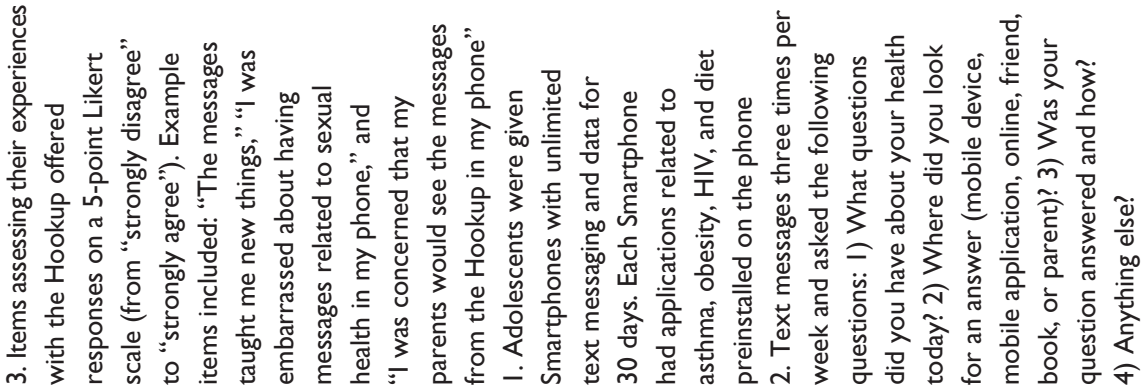

总

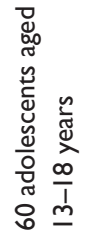

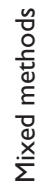
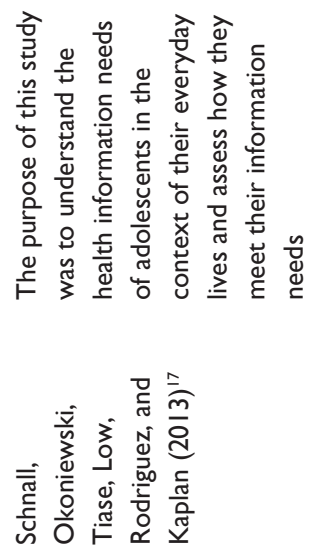


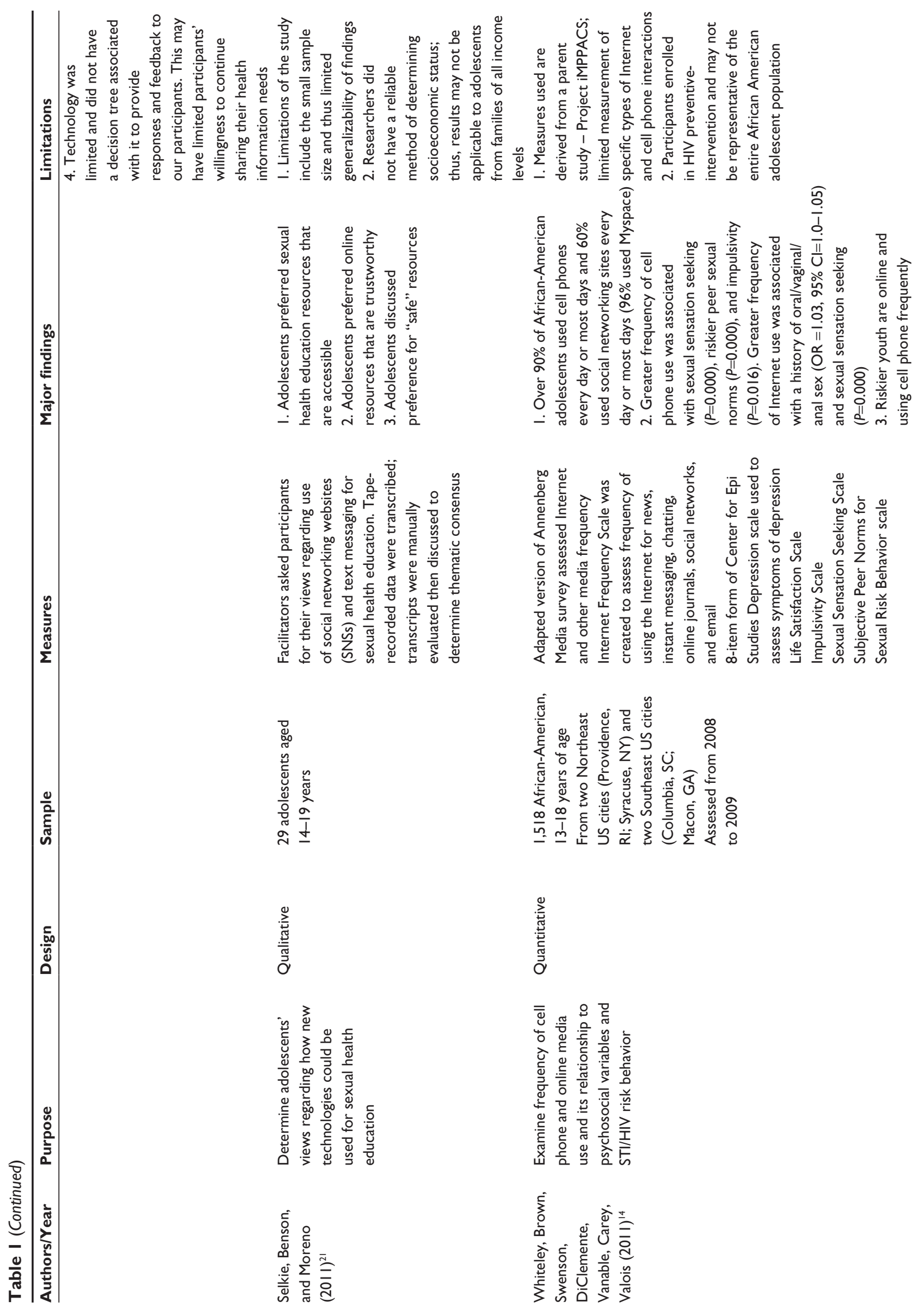



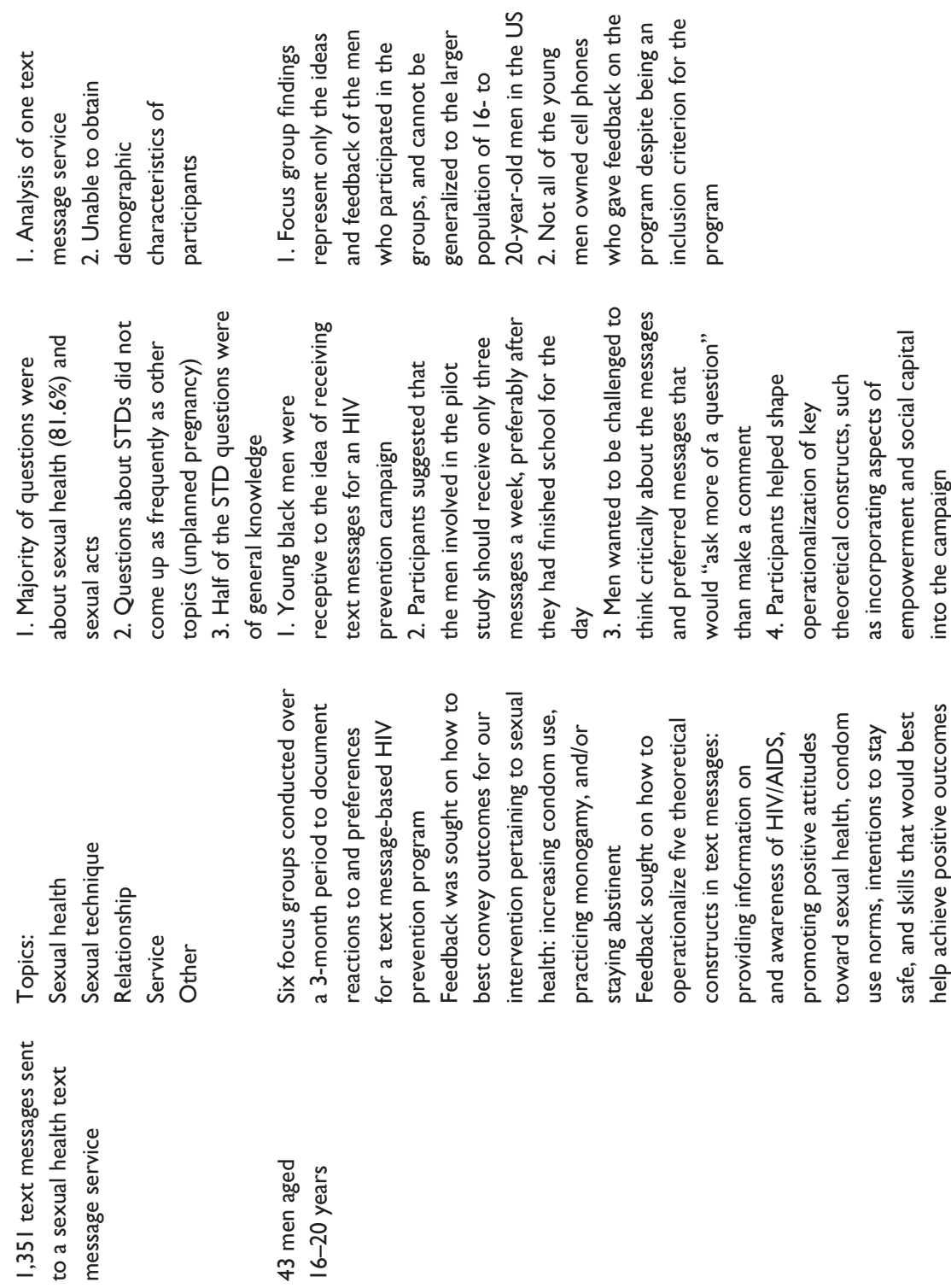

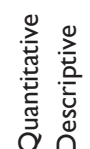

$$
\text { 总 }
$$
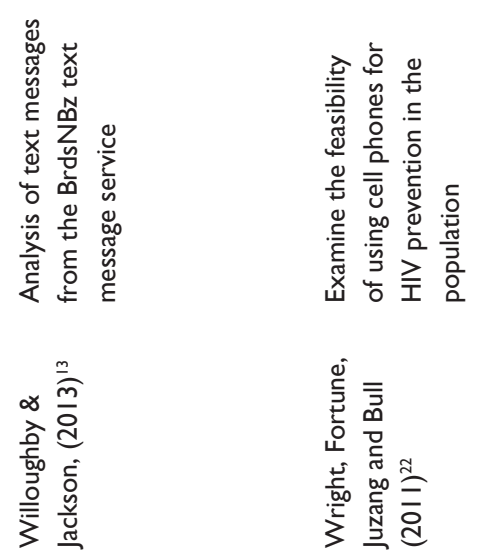
messages/mobile cell phone interventions. ${ }^{17,21}$ In one study, no participants said that they would feel embarrassed if someone viewed their messages and $90 \%$ were unconcerned if their parents saw their messages. ${ }^{21}$ However, they did say that privacy could be compromised, which could make a situation uncomfortable for a teen. In another study, privacy was a consideration with the use of a mobile cell phone safe sex app since participants felt that the research team could see what they were doing with the phones. ${ }^{17}$

\section{Need for tailored messages}

In a follow-up to a mobile cell phone app study, Schnall et $\mathrm{al}^{7}$ found that adolescents 13-18 years of age viewed the app as hard to understand and complicated to use, and thus felt that the app was not tailored to adolescents. This finding is consistent with the conclusion of Selkie et $\mathrm{al}^{21}$ that sexual health resources must be written in clear, understandable language and tailored to adolescents. In addition, Wright et $\mathrm{al}^{22}$ found that their adolescent participants wanted mobile cell phone text messages about STIs, including HIV/AIDS, to be factual and specific to them.

\section{Credible information}

Trust in the information and having someone qualified to respond to questions were found to be challenges in four studies. ${ }^{9,15-17}$ Participants in one study felt that knowing a person was qualified to answer their questions was important in accessing information using mobile cell phones. ${ }^{21}$ In another study, the participants unanimously agreed that they should be able to text questions to their facilitator. ${ }^{15}$ In one study, trained staff members from the Adolescent Pregnancy Prevention Campaign provided medically accurate responses to text messages within 24 hours: typical responses occurred within 3-4 hours. ${ }^{16}$ The cost of having a staff member to answer individual questions may be an issue for communitybased agencies. Yet, youth want an immediate answer to a sexual health question that arises. ${ }^{7,21}$ Automatic standard responses may not always provide an appropriate response or one detailed enough to answer the question.

\section{Impact of age on study outcomes}

In one study, the way text messages were perceived varied depending on the age of the participants. Cornelius et $\mathrm{al}^{7}$ found that age was a primary factor in change in outcome variables. They found greater increases in knowledge, attitudes toward condom use and perceived HIV risk, and more reduction in HIV risk behaviors among older participants (16-18 years of age) than younger participants
(13-15 years of age). The reason why text messages did not resonant among younger participants was unclear. However, the younger participants did report less sexual activity than the older teens, which could explain why the messages did not resonate with them.

\section{Adaptation to other countries: limited access}

Adaptation of mobile cell phone-based interventions to other countries has presented challenges. One of the concerns with technology-based interventions is that we may not reach those who are at the highest risk, partly because of economics and access to services and technology. With low mobile cell phone ownership rates among adolescents in Uganda, only $51 \%$ of the participants in one study indicated that they were somewhat or extremely likely to access HIV/AIDS information via text. ${ }^{18}$ Interest in accessing this information was associated with owning a cell phone. Thus, those at the highest risk may not be able to access cell phones because of the cost of the phone or text messages or data plans.

\section{Use of health care providers}

Only one study identified ways in which health care providers can use a text-messaging service to connect with youth. France examined how a school nurse used text messages to provide students access to her health promotion services. ${ }^{12}$ The challenges with this approach involved administrative time and costs in managing and recording text messages. Advantages to the approach included the fact that it enhanced health services at the school and involved youth by empowering them to become knowledgeable about their sexual health. However, the approach was limited to students who owned or had access to a cell phone. Those without a cell phone did not have access to the services.

\section{Discussion}

Only 17 published articles were found that examined use of mobile cell technology and sexual health. The majority of the articles were descriptive studies that reported text messaging as the primary mode of sending or receiving sexual health information. Only four articles provided findings from a longitudinal study, and these findings were limited to 3-24 months. One study used a one-group design, one was a randomized trial, and one used a nonrandomized control group design.

Our review nonetheless suggests that mobile cell phone interventions are an effective mode for delivering safe sex and sexual health information to youth. However, while studies 
have demonstrated the potential of delivering sexual health information via mobile technology, there is still much to be learned about optimizing this intervention channel. More randomized controlled trials are needed to examine longitudinal effects and varying doses of text messages. Further, one study ${ }^{7}$ has identified possible differential effects of text messaging depending on age. The younger teens in this study also reported less sexual activity than the older teens, which may explain why the messages did not resonate with younger teens. Therefore, it is important to know the population for whom messages are developed: not all messages can be applied to everyone.

Teens want an immediate response to a text message. Automation may be appropriate in many situations, but there are times when a question or the response is not in the database or repository of a sexual health program. It is a challenge to provide real-time responses from staff, but this maybe the only way to be able to provide an answer to every question that may be texted to a sexual health program. Programs such as Hookup ${ }^{20}$ and $\mathrm{BrdsNBz}^{13}$ have found success in providing text-automated responses to messages but data are limited on the long-term effectiveness of these programs.

There is a cost for delivering mobile cell phone messages or interventions. Participants and staff must have working equipment and unlimited text messaging and data plans. Those most at risk may not have cell phones and may not be able to access safe sex messages; therefore, alterative means for delivering safer sex messages must be found. Further, lost or damaged equipment remains a challenge and research staff may need to provide phones on loan to reduce dropout rates in studies.

\section{Recommendations}

Excessive use of text messaging affects adolescent social development negatively. ${ }^{24}$ It would be interesting to do a longitudinal study to see whether text messaging drops off when social skills develop. Case scenarios could be developed to see how participants interact with others, measuring eye contact, word fillers, and body language against their textmessaging rates. ${ }^{24}$

Currently, text messaging is an acceptable form of receiving sexual health information among adolescents, but in this review, we found no studies with follow-up beyond 24 months. Future studies should examine participant attrition, plans for improving retention, and message boosting to encourage maintenance of behavior change. In one study the researchers sent text-messaging boosters to augment a face-to-face intervention, and this enhanced effects. We must also begin to investigate other sources of sexual health communication. Currently, social media networks are being examined as potential sexual health information sources among adolescents. Platforms deploying multiple technologies may be particularly successful. For example, with a social media intervention that uses multiple sites, youth only need to $\log$ into one site. Given the long interval between mobile cell phone intervention development and dissemination, it is also important to assess not only the current user population but also potential future populations.

Sexual health interventions should go where the population goes. Real time interventions will have the greatest impact. As newer types of media become increasingly available and used by adolescents, it may be important to study different types of cell phone interactions and their associations with sensation seeking and impulsivity.

The lack of theory-based interventions found in this review may reflect the current focus on clinical care rather than on preventive health behavior change. However, interventions built on theory may have the greatest potential to change behavior and empower youth with the skills to practice abstinence or safe sex behaviors. Further, as technologies continue to develop, assessments should be performed prior to launching a program using new technology to ensure that the technology platform is still relevant to the target audience. New technology should augment, not replace existing resources.

Only one study ${ }^{23}$ reviewed here identified dissemination of a mobile safe sex information via a website. The website augmented information from an intervention and demonstrated one method of broad dissemination of safe sex information for adolescents. This website had a global impact, reaching unique users in 61 different countries. Future research should further examine the global impact of text-messaging interventions with participants in different countries.

More research is also needed to examine technologybased sexual communications among youth, since these have implications for adolescents' safe sex decision-making. Timing, quality, length, and commitment of relationships should be examined with the mobile cell phone communication process. In addition, parent-child mobile cell phone-based interventions may improve adolescents' safe sex decisionmaking since parents have been identified as a factor in the delay of their child's sexual debut.

Further, we need to examine sexting behaviors across geographic regions by format (photo, text) and medium (cell phone, email, etc) and relationships to sexual activities. 
Future research should also examine parents' perceptions of their child's cell phone use and compare this with the child's actual self-reported usage for sexual risks. Since sexting has been identified as a prelude to sexual intercourse, parents and health care providers should begin discussions of technology use with teens to identify possible sexual risks. Finally, research is needed to find out what youth do with the information that they use on text-generated sites (such as Hookup and SexInfo) and the extent in which the information is found helpful.

One strength of this review is the multiple strategy search process used. Further, the time frame was limited to the last 5 years, providing the most recent studies on this topic. The limitations of the review include the fact that many of the studies reviewed were pilot or exploratory studies with small purposive samples limiting generalizability of the findings. In addition, the review was limited by having only one article from Africa, where rates of HIV infection are the highest in the world.

\section{Conclusion}

This systematic review provides useful information on the impact of technology on the delivery of safe sex information to youth. Additional research is needed to identify the most effective approaches to using mobile cell phones as a vehicle for providing sexual health information to youth. There remain challenges, however, in the delivery of mobile cell phone safe sex interventions. One challenge is that young participants may not own a cell phone or have access to one. Another is that we do not know about the long-term effectiveness of mobile phone sexual health interventions. Further, messages must be tailored to the targeted population who need to be involved with the research planning from the ground up. Technical problems must be identified early and corrected as soon as possible to prevent attrition; this may require the constant presence of a technology specialist with the project. Finally, some text messages or data plans may incur a cost, which could be a barrier to implementation.

\section{Disclosure}

The authors report no conflicts of interest in this work.

\section{References}

1. Centers for Disease Control and Prevention (CDC). CDC fact sheet: Incidence, prevalence of sexually transmitted diseases in the United States. Published February 2013. Available from: http://www.cdc.gov/ std/stats/sti-estimates-fact-sheet-feb-2013.pdf. Accessed September 22, 2015.
2. Centers for Disease Control and Prevention (2015). Youth behavior surveillance survey. Published May 15, 2015. Available from: http:// www.cdc.gov/healthyyouth/data/yrbs/index.htm. Accessed September 22, 2015.

3. Pew Research Center. Teens and technology 2013. Published March 13, 2013. Available from: http://www.pewinternet.org/files/old-media/Files/ Reports/2013/PIP_TeensandTechnology2013.pdf. Accessed September 22, 2015.

4. National Institutes of Health. Frequently asked questions. Published March 17, 1999. Available from: http://grants.nih.gov/grants/funding/ children/pol_children_qa.htm. Accessed September 22, 2015.

5. World Health Organization. Adolescent health. Published 2015. Available from: http://www.who.int/topics/adolescent_health/en/. Accessed September 22, 2015.

6. Miles M, Huberman A. Qualitative Data Analysis. 2nd ed. Thousand Oaks CA: Sage; 1994.

7. Cornelius JB, Dmochowski J, Boyer C, St. Lawrence JS, Lightfoot M, Moore M. Text messaging enhanced HIV interventions for African American adolescents: a feasibility study. $J$ Assoc Nurses AIDS Care. 2012;24(3):256-367.

8. Katz KS, Rodan M, Milligan R, Tan S, Courtney L, et al. (2011) Efficacy of a randomized cell phone-based counseling intervention in postponing subsequent pregnancy among teen mothers. Matern Child Health $J$. 15 (Suppl 1): S42-S53.

9. Juzang I, Fortune T, Black S, Wright E, Bull S. A pilot programme using mobile phones for HIV prevention. $J$ Telemed Telecare. 2011;17(3);150-153.

10. Fortune T, Wright E, Juzang I, Bull S. Recruitment, enrollment, and retention of young black men for HIV prevention research: experiences from the 411 for Safe Text Project. Contem Clin Trials. 2010;31: 151-156.

11. Buhi ER, Klinkenberger N, Hughes S, Blunt HD, Rietmeijer C. Teens' use of digital technologies and preferences for receiving STD prevention and sexual health promotion messages: implications for the next generation of intervention initiatives. Sex Trans Dis. 2013;40(1): $52-54$.

12. France J. Using texts to increase access to school nurses. Nurs Times. 2014;110(13):18-19.

13. Willoughby JF, Jackson K. Can you get pregnant when u r in the pool? Young people's information seeking from a sexual health text line. Sex Ed. 2013;13(1):96-106.

14. Whiteley LB, Brown LK, Swenson, et al. African American adolescents and new media: associations with HIV/STI risk behavior and psychosocial variables. Ethn Dis. 2011;21(2):216-222.

15. Cornelius JB, Cato M, St. Lawrence JS, Boyer CB, Lightfoot M. Development and pretesting multimedia HIV-prevention text messages for mobile cell phone delivery. J Assoc Nurs AIDS Care. 2011;22(5): 407-413.

16. Devine S, Bull S, Dreisbach S, Shlay J. Enhancing a teen pregnancy prevention program with text messaging: Engaging minority youth to develop TOP ${ }^{\circledR}$ Plus Text. J Adolesc Health. 2014;54(3):S78-S83.

17. Schnall R, Okoniewski A, Tiase V, Low A, Rodriguez M, Kaplan S. Using text messaging to assess adolescents' health information needs: an ecological momentary assessment. J Med Internet Res. 2013;15(3):1-16.

18. Mitchell KJ, Bull S, Kiwanuka J, Ybarra ML. Cell phone usage among adolescents in Uganda: acceptability for relaying health information. Health Educ Res. 2011;26(5):770-781.

19. Cornelius JB, St. Lawrence JS, Howard JC, et al. Adolescents' perceptions of a mobile cell phone text messaging-enhanced intervention and development of a mobile cell phone-based HIV prevention intervention. J Spec Pediatr Nurs. 2012;17:61-69.

20. Perry RC, Kayekjian KC, Braun RA, Cantu M, Sheoran B, Chung PJ. Adolescents' perspectives on the use of a text messaging service for preventive sexual health promotion. J Adolesc Health. 2012;51(3):220-225. 
21. Selkie EM, Benson M, Moreno M. Adolescents'views regarding uses of social networking websites and text messaging for adolescent sexual health education. Am J Health Educ. 2011;42(4):205-212.

22. Wright E, Fortune T, Juzang I, Bull S. Text messaging for HIV prevention with young Black men: formative research and campaign development. AIDS Care. 2011;23(5):534-541.

23. Cornelius JB, Cato MG, Toth JL, Bard PM, Moore MW, White A. Following the trail of an HIV-prevention web site enhanced for mobile cell phone text messaging delivery. J Assoc Nurses AIDS Care. 2012;23(3):255-259.
24. LaBode V. Text messaging: one step forward for phone companies, one leap backward for adolescence. Int J Adolesc Med Health. 2011;23(1). 65-71.

\section{Publish your work in this journal}

Adolescent Health, Medicine and Therapeutics is an international, peer-reviewed, open access journal focusing on health, pathology, and treatment issues specific to the adolescent age group. All aspects of health maintenance, preventative measures and disease treatmen interventions are addressed within the journal and practitioners from all disciplines are invited to submit their work as well as healthcare researchers and patient support groups.. The manuscript management system is completely online and includes a very quick and fair peerreview system. Visit http://www.dovepress.com/testimonials.php to read real quotes from published authors.

Submit your manuscript here: http://www.dovepress.com/adolescent-health-medicine-and-therapeutics-journal 